\title{
Exposure to ethanol and tobacco smoke in relation to level of PCNA antigen expression in pancreatic and hepatic rat cells
}

\author{
Ewa Wiśniewska ${ }^{1}$, Anna Dylik ${ }^{1}$, Maksymilian Kulza², Ewa Florek², \\ Wojciech Piekoszewski3,4, Monika Seńczuk-Przybyłowska², \\ Andrzej Marszałek 1,5 \\ ${ }^{1}$ Department of Clinical Pathomorphology, Ludwik Rydygier Collegium Medium Bydgoszcz, Nicolaus Copernicus \\ University in Toruń, Skłodowskiej-Curie 9, PL-85-094 Bydgoszcz, Poland \\ ²Laboratory of Environmental Research, Department of Toxicology, University of Medical Sciences, Dojazd 30, \\ PL 60-631 Poznań, Poland \\ ${ }^{3}$ Department of Analytical Chemistry, ${ }^{4}$ Laboratory of High Resolution Mass Spectrometry, Faculty of Chemistry, \\ Jagiellonian University, Ingardena 3, PL 30-060 Kraków, Poland \\ ${ }^{5}$ Department of Oncologic Pathology, University of Medical Sciences, and Wielkopolskie Oncology Center, \\ Garbary 15, PL 61-868 Poznań, Poland
}

Correspondence: Andrzej Marszałek, e-mail: amars@cm.umk.pl

\begin{abstract}
:
Background: Previous results proved that simultaneous effect of tobacco smoke constituents and alcohol consumption may change toxicity of these substances and have a greater effect on hepatic and pancreatic disease and cancer risk. The aim of this study was to investigate hepatocyte and pancreatic cells regeneration after tobacco and/or ethanol treatment.

Methods: In the study, four groups of rats were used - alcohol non-addicted and addicted male and female rats. The animals from each group were exposed to tobacco smoke, to ethanol or tobacco smoke and ethanol. After the exposure, pancreas and liver were collected at two time-points -5 and $24 \mathrm{~h}$. Biochemical methods were used to measure concentration of ethanol and cotinine in blood and plasma. Additionally, proliferating cell nuclear antigen labeling index (PCNA-LI), an S-phase marker was assessed by immunohistochemical staining and morphometric method.

Results: Our experimental results showed that the exposure of rats to tobacco smoke does not have influence on ethanol concentration in blood of non-addicted (male, female) and addicted (male and female) animals. The results also proved that alcohol addiction did not influence nicotine metabolism in all animals exposed to tobacco smoke. Morphological studies of tissues display significant damage in liver of addicted males, including fatty degradation, fibrosis and slight inflammatory infiltrate. Immunohistochemical studies revealed at first, significant increase of PCNA-LI and, thus, increased cell proliferation activity and damage in tissues were observed in hepatic and pancreatic cells of addicted males when compared with non-addicted males. Secondly, comparison between addicted males and addicted females revealed that PCNA-LI in females is significantly lower, both in hepatic and pancreatic tissues. And finally, animals exposed only to ethanol and to tobacco smoke plus ethanol were characterized by higher percentage of PCNA positive cells in relation to animals exposed only to tobacco smoke.

Conclusion: From the preliminary study one can conclude that the influence of ethanol and simultaneous influence of ethanol and tobacco smoke impairs liver and pancreatic functions to a greater degree than tobacco abuse.
\end{abstract}

Key words:

ethanol, liver, pancreas, PCNA, proliferative activity, tobacco smoke 
Abbreviations: ADH - alcohol dehydrogenase, ALD - alcoholic liver disease, ALDH - aldehyde dehydrogenase, BSA bovine serum albumin, EDTA - ethylenediaminetetraacetic acid, ELISA - enzyme-linked immunosorbent assay, FAEE fatty acid ethyl esters, PBS - phosphate buffered saline, PCNA - proliferating cell nuclear antigen, PCNA-LI - proliferating cell nuclear antigen labeling index

\section{Introduction}

Both tobacco smoking and alcohol misuse are severe medical, sociological and economical problems in a world scale. Alcohol and cigarette smoke usually lead to major health risk when used alone and together [38].

Ethyl alcohol is a highly toxic substance that, if concentrated enough, has a damaging effect on almost all systemic organs including brain, kidney, heart, gastrointestinal tract, lung, pancreas and most frequently liver $[2,10,15,22,40]$. Alcoholic liver disease (ALD) is better characterized than in other organs. Long-term alcohol abuse may induce alcoholic hepatitis and alcoholic cirrhosis, potentially followed by primary hepatocellular carcinoma development [1,22].

However, in tobacco smoke there are over 4300 chemical compounds, 50 of which are carcinogenic. In previous studies, it was unambiguously showed that a chronic exposure to tobacco smoke increases the incidence of cancer as well as respiratory, gastrointestinal and cardiovascular diseases. Moreover, our previous results showed negative influence of smoking on rats' fertility and reproduction; it causes pregnancy disorders and negatively affects the fetal development $[17,18]$.

Almost $90 \%$ of ethyl alcohol is metabolized in the liver, where acetaldehyde is produced as a result of oxidation. This compound is ten times more toxic than ethanol itself. The rest of ethanol is metabolized in gastric mucosa, kidneys, pancreas, muscles, lungs, spleen and brain [30]. The main enzyme oxidizing ethanol into acetaldehyde is cytosolic alcohol dehydrogenase $(\mathrm{ADH})$ and in case of long-lasting alcohol consumption - CYP2E1 [33]. Ethanol can also be oxidized in liver peroxisomes by catalase, however, this mechanism is less significant. In further transitions, aldehyde dehydrogenase (ALDH) catalyses oxidation of acetaldehyde to acetate, this in turn is converted into acetyl-CoA. Then, the coenzyme is incorporated into the Krebs cycle and oxidized to carbon dioxide and water [25]. An increased level of acetaldehyde in the liver leads to hepatic mitochondrial damage, thus resulting in secondary inhibition of fatty acids ethyl esters (FAEE) oxidation [22]. Additionally, an impairment of secretion mechanisms may be observed. Cumulative effect of both these processes cause hepatic cells steatosis [1].

Similarly to the liver, the pancreas has the capacity to metabolize alcohol via both oxidative (ADH, ALDH, CYP2E1 and catalase) and nonoxidative pathways yielding toxic metabolites such as acetaldehyde and FAEE. Their concentration significantly increases after long-term alcohol consumption [25]. Although it is evident that alcohol can have an important role in the development of $70-80 \%$ of all chronic pancreatitis cases $[51,52]$, it does not appear that alcohol abuse alone is responsible for the development of pancreatitis. Ethanol rather sensitizes the pancreas to injury and other factors are required to develop alcoholic pancreatitis. Cigarette smoking, high lipid diet, virus infections and genetics factors have been suggested as possible cofactors [41].

In addition, pancreas is one of the organs where metabolic processes of tobacco smoke constituents take place. It was demonstrated that such substances activate histopathological alterations in pancreas that can result in exocrine and endocrine dysfunction of this organ. Many diseases of pancreas are tobacco smoke related, e.g., pancreatitis, diabetes, gallstone pancreatitis. Nicotine present in tobacco smoke is causing various histopathological changes in rats' tissues, accompanied by cytoplasmic vacuolization, interstitial cell edema, necrosis and karyolysis [12]. Additionally, there is a $70 \%$ higher risk of pancreatitis and malignant changes in smokers in comparison to non-smokers $[12,46]$.

A combined use of alcohol and tobacco smoke is often observed and some studies have reported that both these stimulants may work synergistically to increase the risk of liver and pancreas cancers [35]. It is known that the same enzymes are involved in alcohol and nicotine biotransformation, inter alia aldehyde oxidase and cytochrome P-450 isoforms, such as CYP2E1 and CYP2B1/2 [42]. Studies show that consuming tobacco and alcohol together can augment the pleasure users experience from either substance alone. Prior studies have demonstrated that nicotine administration via tobacco smoke increased alcohol consumption both in humans [5] and in animals [31]. On the contrary, Rose and colleagues [39] showed that alcohol drinking could enhance satisfaction from smoking cigarettes. These results highlight the potent interactions between ethanol consumption and tobacco smoking. 
Possible common mechanism interactions of these substances need to be explained but simultaneously these are very difficult to study because alcohol and nicotine can affect people differently depending on the gender, age, amount consumed, overweight, hepatitis $\mathrm{C}$ infection, genetic factors, polymorphism(s) of alcoholand tobacco-metabolizing enzymes and many other factors. Evidences suggest that the common effect of nicotine and ethanol is related to stimulation of particular receptors: nicotine cholinergic receptor and $\mathrm{D}_{2}$ dopamine receptor [31] followed by activation of the mesolimbic dopamine system. Chronic administration of these harmful substances could produce functional changes in this important part of brain reward system [49]. It is worth noticing that when nicotinic receptors are blocked, people not only tend to consume less nicotine [13] but also less alcohol [48]. It may be the basis for addiction and may explain some of the interactions between alcohol and tobacco.

The liver and the pancreas are developmentally very closely related and have a tremendous capacity to regenerate after injury $[3,14,50]$. Moreover, pancreatic stellate cells appear to be morphologically and functionally similar to hepatic stellate cells [7] and react to alcohol abuse in a similar way. All of these similarities recognized between hepatic and pancreatic cells would suggest that the regenerative process, and the effects of ethanol on this process, may be similar in the pancreas and the liver [45]. In this study, we investigated the effects of ethanol feeding for 9 weeks and then single animals' exposition to tobacco smoke, to ethanol or tobacco smoke and ethanol simultaneously on the regeneration process of animals' liver and pancreas. We assessed regeneration capacity by immunohistochemical staining of proliferating cell nuclear antigen (PCNA). In this article, we briefly explore the association between alcohol consumption and smoking.

\section{Materials and Methods}

\section{Animal experiments}

White Wistar male and nongravid female rats were used in the project. They were 3 months old and their average weight was $189 \mathrm{~g}$ for females and $361 \mathrm{~g}$ for males. Male and female Wistar rats from the Department of Toxicology, University of Medical Sciences in Poznań, were housed in polycarbonate cages with hardwood chip bedding. A standard laboratory diet and water were available with no limitations. Throughout the entire study period, a 12/12 h light/ dark cycle was maintained. Females and males were kept apart, in separate animal quarters and acclimatize during 14 days.

The process of animal addiction with ethyl alcohol took 9 weeks. One month old rats, 200 males and 200 females, were used in the first stage of the experiment. The necessary number of alcohol addicted rats was subsequently selected from this group. A schematic illustration of the experimental protocol is presented in Figure 1.

The process of alcohol addiction:

Week I - animals received $10 \%$ ethyl alcohol solution to drink.

Week II and III - animals could choose either water or $10 \%$ ethyl alcohol solution to drink.

Week IV - animals were transferred into single cages, they could choose either water or $10 \%$ ethyl alcohol solution to drink. The amount of drank liquids was measured each day.

Week V and VI - animals received only water to drink.

Week VII and VIII- animals could choose either water or $10 \%$ ethyl alcohol solution to drink.

Week IX - animals kept in single cages could choose either water or $10 \%$ ethyl alcohol solution to drink. The amount of drank liquids was measured each day.

Based on the measurement, animals were divided into four groups of alcohol addicted and non-addicted individuals. The first control group consisted of 18 non-addicted males, the second control group consisted of 18 non-addicted females, the third group consisted of 18 addicted males and the fourth group consisted of 18 addicted females.

Animals were qualified as addicted when they drank alcohol volume amounted to: males: $10-37 \%$ total amount of liquids drunk, females: $7-20 \%$ total amount of liquids drunk.

Rats in each experimental group (non-addicted male and female, addicted male and female) were divided into three subgroups (A, B and C):

A - animals were exposed to tobacco smoke for $6 \mathrm{~h}$ per day, for 5 days. CO concentration was taken as an index of tobacco smoke concentration and was maintained at $1500 \mathrm{mg} \mathrm{CO} / \mathrm{m}^{3}$. Rats were exposed in a dynamic toxicological chamber [16] to tobacco smoke generated from a Polish brand of cigarettes without 
Fig. 1. Schematic representation of animal groups and experimental protocol. Details described in Materials and Methods section. $n$ - number of rats; $S$ - sacrifice

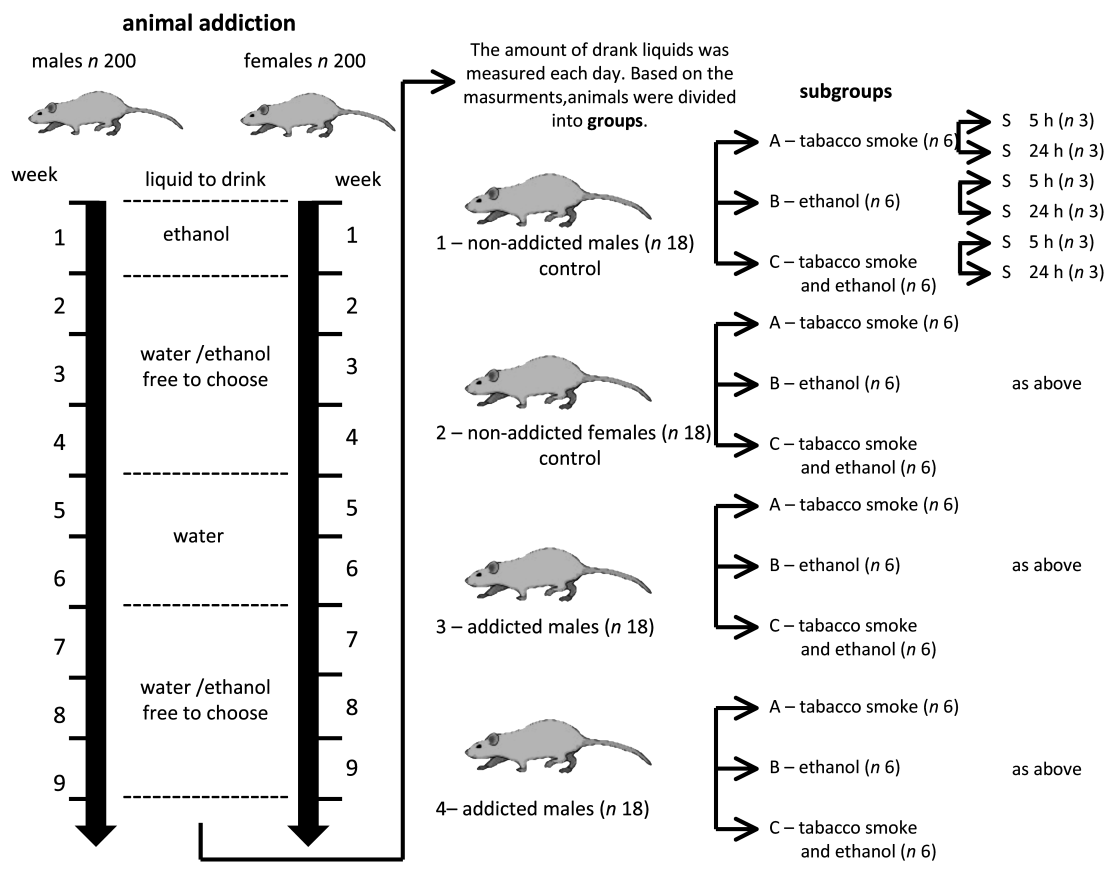

a filter tip ("Poznańskie" - Imperial Tobacco Polska S.A., Poznań, Poland);

$\mathrm{B}$ - an alcohol solution (10\%) at a dose of $2 \mathrm{~g} / \mathrm{kg}$ was given by gavage in a single dose;

$\mathrm{C}$ - animals were exposed to tobacco smoke for $6 \mathrm{~h}$ per day, for 5 days. Rats were exposed to a $10 \%$ alcohol solution at a dose of $2 \mathrm{~g} / \mathrm{kg}$, administered by gavage in a single dose. $\mathrm{CO}$ concentration was taken as an index of tobacco smoke concentration and was maintained at $1,500 \mathrm{mg} \mathrm{CO} / \mathrm{m}^{3}$.

After exposure to tobacco smoke (group A) or administration of alcohol (groups B and C), animals were anesthetized (xylocaine $40 \mathrm{mg} / \mathrm{kg}$ and ketamine $5 \mathrm{mg} / \mathrm{kg}$ ) and pancreas and liver were collected at two time points ( 5 and $24 \mathrm{~h}$ ) with three rats per point.

The protocol of animal experiment was approved by the Local Ethics Commission for Animal Studies in Poznań - No. 02/2008 January $18^{\text {th }} 2008$.

\section{Cotinine determination}

Cotinine concentration was measured by an enzymelinked immunosorbent assay (ELISA) with the application of reagents for Cotinine Direct Elisa from BioQuant (San Diego, USA). All determinations were performed according to the manufacturer's instructions. The linear range of determination was 5$500 \mu \mathrm{g} / 1$ of cotinine, the limit of detection was $1 \mu \mathrm{g} / \mathrm{l}$, and the limit of determination was $5 \mu \mathrm{g} / \mathrm{l}$. The inter- and intraday coefficients of variation for 5, 50, and $100 \mu \mathrm{g} / \mathrm{l}$ of cotinine were below $10 \%$.

\section{Ethanol determination}

Ethanol concentration was determined by REA (radiative energy attenuation) using the AxSYM analyzer and Abbott reagents (Illinois, USA). All determinations were performed according to the manufacturer's instructions. The linear range of determination was $0.1-3.0 \mathrm{~g} / 1$ of ethanol, the limit of detection was $0.052 \mathrm{~g} / 1$, and the limit of determination was $0.1 \mathrm{~g} / \mathrm{l}$. The inter- and intraday coefficients of variation for $0.5,1.0$ and $1.5 \mathrm{~g} / \mathrm{l}$ of ethanol were below $10 \%$.

\section{Tissue processing}

Liver and pancreas of the rats were fragmented into pieces and subsequently preserved in 4\% paraformaldehyde in phosphate buffer (46 mM Na $2 \mathrm{HPO}_{4}$, $30 \mathrm{mM} \mathrm{NaH} \mathrm{PO}_{4}, \mathrm{pH} \mathrm{7.3)}$ for $24 \mathrm{~h}$. The biological material was repeatedly rinsed with water, dehydrated in a sequence of ethanol solutions with increasing concentrations, in xylene and then supersaturated and paraffin embedded. All stages of tissues preparation were conducted at $24^{\circ} \mathrm{C}$. The paraffin samples were cut on microtome Accu-Cut SRM 200 (Sakura Finetek Europe B.V., Alphen aan den Rijn, Netherlands) with a steel knife. The obtained $4 \mu \mathrm{m}$ thick sections 
were located on silane-coated microscope slides (Thermo Scientific, Waltham, MA, USA) both for hematoxylin and eosin (HE) staining and immunohistochemical study. There was no-available material derived from non-addicted females for histo- and immunohistochemical evaluation.

\section{Histological examination}

We used a standardized protocol. In brief, at the first stage of histochemical and immunohistochemical reaction the paraffin was removed from sections with xylene. The slices were subsequently subjected to treatment with numbers of alcohol solutions with decreasing concentrations in order to hydrate the tissues. Deparaffinized tissue sections were stained with HE, mounted in Shandon Consul Mount resin (Thermo Scientific, Waltham, MA, USA), and viewed under a light microscope and photographed. The slides were microscopically evaluated for presence of inflammation, hepatic and pancreatic foci of cellular alternation, hyperplasia or hypertrophy. The sections were examined by two independent investigators.

\section{Immunohistochemistry of PCNA}

Deparaffinized sections were incubated in $\mathrm{pH} 8.0$ EDTA solution in water bath, at $95^{\circ} \mathrm{C}$ for $40 \mathrm{~min}$ for retrieval of antigens. After cooling down, the sections were treated with $3 \%$ hydrogen peroxide solution for inhibition of endogenous peroxide. The following steps of the study were conducted at room temperature. The material had been blocked with 5\% BSA in PBS buffer (138 mM NaCl, $30 \mathrm{mM} \mathrm{Na} \mathrm{HPO}_{4}, 2 \mathrm{mM}$ $\mathrm{KH}_{2} \mathrm{PO}_{4}, \mathrm{pH} 7.3$ ) for $10 \mathrm{~min}$ and incubated with PCNA antibody (Novocastra, Leica Microsystems, Wetzlar, Germany) diluted in PBS buffer with $1 \%$ BSA ( 1 : 100 proportion) for $1 \mathrm{~h}$. Horseradish peroxidase conjugated anti-mouse secondary antibodies (Dako EnVision system) were used for detection (Dako, Glostrup, Denmark). A 30-min incubation followed by visualization of antigens with 3,3'-diaminobenzidine (Dako, Glostrup, Denmark) used as chromogen was performed. After immunohistochemical reaction, the samples were stained with hematoxylin, dehydrated, immersed in xylene and encased in Shandon Consul Mount resin. The stage of tissue incubation with primary antigen was omitted in the control reaction.

\section{Morphometric analysis}

The PCNA antigen expression level was determined based on the measurement of cell nuclei staining intensity in the analyzed tissues of pancreas and liver in rats. A four-grade scale from 0 to 3 was applied, where 0 meant lack of and 3 high intensity of staining of nuclei. After immunohistochemical reaction, five photographs of randomly selected fields of each of 108 microscopic preparations (54 livers and 54 pancreases) were taken in compliance with sampling conditions for image analysis. Photographs were taken with a Jenamed 2 light microscope (Carl Zeiss, Germany) equipped with cooled CD camera (Nikon Digital Sight DS-5Mc, Germany) driven by NIS Elements F 3.0 software (Nikon, Germany). Afterwards the photographs were analyzed with ImageJ 1.41 o (National Institute of Health, Bethesda, MD, USA) computer software. Cells were manually calculated by clicking the image, in order to count PCNA labeling index (PCNA-LI). Each click marks the cell with a colored square and adds the cell to a tally sheet. Each photograph was analyzed two times. At first, all visible in photograph nuclei were counted and finally, nuclei that were stained to level 3 according to applied scale. Different groups were marked up with different color squares and they were tallied separately. After counting, the results were saved as .xls Excel spreadsheet and analyzed. PCNA-LI was defined as the percentage of cells with nuclei stained to level 3 in the total number of counted cells [21].

\section{Statistical analysis}

Statistical analysis was performed by using statistical package GraphPad Prism version 5 for Windows. Data are presented as the means and the standard division (SD) of the values of 3 rats belonging to a particular experimental group/subgroup. All results were presented in tables. The comparison between groups (non-addicted males vs. addicted males) was made by Mann-Whitney U test, while Bonferroni's multiple comparison test was used to examine whether in subgroups of rats - (A) tobacco smoke, (B) ethanol, and (C) tobacco smoke and ethanol - significance differences existed. The data were considered statistically significant when $\mathrm{p}<0.05$. 
Tab. 1. Concentration of ethyl alcohol and cotinine in studied groups. Information about groups and exposure see Materials and Methods

\begin{tabular}{|c|c|c|c|c|c|c|c|}
\hline \multirow{3}{*}{ Studied group } & \multirow{3}{*}{$\begin{array}{c}\text { Exposure } \\
\text { Time } \\
\text { (h) }\end{array}$} & \multicolumn{6}{|c|}{ Subgroup } \\
\hline & & $\begin{array}{l}\text { A - tobacco } \\
\text { smoke }\end{array}$ & $\begin{array}{l}\text { B - ethyl } \\
\text { alcohol }\end{array}$ & $\begin{array}{c}\mathrm{C} \text { - tobacco smoke } \\
\text { and ethyl alcohol }\end{array}$ & $\begin{array}{l}\text { A - tobacco } \\
\text { smoke }\end{array}$ & $\begin{array}{l}\text { B - ethyl } \\
\text { alcohol }\end{array}$ & $\begin{array}{l}\mathrm{C} \text { - tobacco smoke } \\
\text { and ethyl alcohol }\end{array}$ \\
\hline & & \multicolumn{3}{|c|}{$\begin{array}{l}\text { Blood ethyl alcohol concentration } \\
\qquad(\mathrm{g} / \mathrm{l})\end{array}$} & \multicolumn{3}{|c|}{$\begin{array}{l}\text { Plasma cotinine concentration } \\
\qquad(\mu \mathrm{g} / \mathrm{l})\end{array}$} \\
\hline \multirow{2}{*}{$\begin{array}{l}1 \text { - non-addicted male } \\
\text { (control) }\end{array}$} & 5 & 0 & $0.27 \pm 0.27$ & $0.37 \pm 0.20$ & $49.4 \pm 11.6$ & 0 & $44.7 \pm 13.5$ \\
\hline & 24 & 0 & 0 & 0 & $32.7 \pm 9.87$ & 0 & $23.8 \pm 7.3$ \\
\hline \multirow{2}{*}{$\begin{array}{l}2 \text { - non-addicted female } \\
\text { (control) }\end{array}$} & 5 & 0 & $0.20 \pm 0.17$ & $0.06 \pm 0.10$ & $56.3 \pm 0.0$ & 0 & $29.4 \pm 6.7$ \\
\hline & 24 & 0 & 0 & 0 & $5.2 \pm 0.0$ & 0 & $5.6 \pm 1.2$ \\
\hline \multirow{2}{*}{3 - addicted male } & 5 & 0 & $0.25 \pm 0.28$ & $0.69 \pm 0.42$ & $47.7 \pm 14.4$ & 0 & $42.4 \pm 16.9$ \\
\hline & 24 & 0 & 0 & 0 & $37.6 \pm 5.6$ & 0 & $31.6 \pm 8.9$ \\
\hline \multirow{2}{*}{4 - addicted female } & 5 & 0 & $0.64 \pm 0.24^{\mathrm{a}}$ & $0.65 \pm 0.34$ & $55.5 \pm 15.7$ & 0 & $51.2 \pm 7.8$ \\
\hline & 24 & 0 & 0 & 0 & $30.7 \pm 8.6$ & 0 & $25.9 \pm 9.9$ \\
\hline
\end{tabular}

a means significant differences $(p<0.05)$ in concentration of ethyl alcohol and cotinine in groups B or $C$ vs. group $A$

\section{Results}

An influence of tobacco smoke, ethanol and both of these factors administered simultaneously on rats' liver and pancreas regeneration were investigated. The tobacco smoke exposition and ethanol dependence models have been developed in our previous projects $[19,20]$.

\section{Concentration of ethanol and cotinine in blood and plasma}

Gender, as well as ethanol dependence of animals enrolled in the experiment, were taken into consideration in the assessment of the influence of detrimental agents on the condition of both affected organs. The concentration of cotinine and ethanol in blood of studied animals is presented in Table 1. Exposure of rats to tobacco smoke does not have influence on ethanol concentration in blood of non-addicted (male, female) and addicted (male and female) animals. However, statistically higher concentration of ethanol was noticed in blood of addicted female than in non-addicted and addicted male rats in case of rats non-exposed to tobacco smoke. The results also proved that alcohol addiction did not influence nicotine metabolism in all animals exposed to tobacco smoke, cotinine concentrations were on a similar level. Lack of interactions between nicotine and ethyl alcohol was observed for animals being under influence of alcohol at the moment of blood sampling and for animals with no alcohol in their blood.

\section{Morphological and histopathological observations}

HE staining (Fig. 2a-d) of paraffin-embedded tissue sections of liver and pancreas revealed a normal histoarchitecture in the control group (non-addicted male), while fatty changes in the liver as well as some degree of derangements in pancreatic samples were observed in the tissues of addicted animals.

\section{Proliferation studies}

The presence, distribution and, most importantly, expression level of a PCNA protein, which is established cell proliferation marker, were assessed in the scheduled experiments.

In the analyzed samples under a light microscope, visually observed brown signals indicating the location of PCNA protein had varying intensity (Fig. $2 \mathrm{e}-\mathrm{h}$ ). This determined the level of expression of the antigen. The microscopic observations of numerous preparations proved that the PCNA antigen is present mainly in cellular nuclei (Fig. 2e-h). Only sparse cells of both organs had PCNA protein in cytoplasm (Fig. 

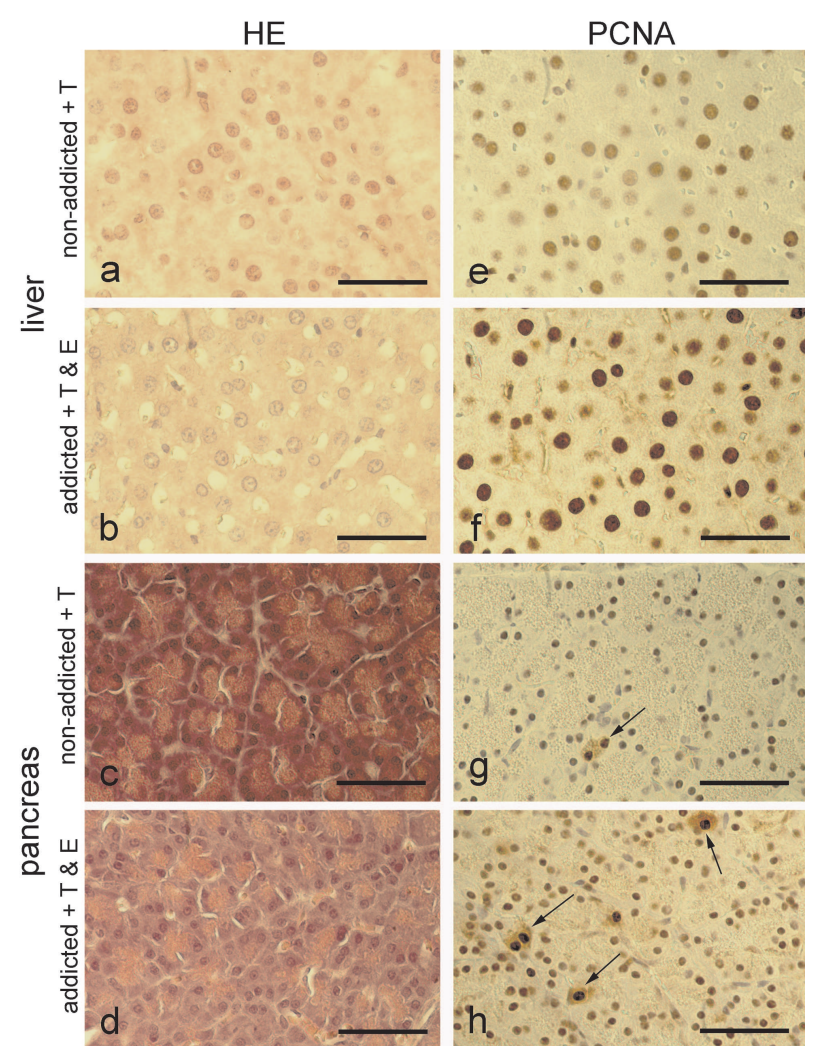

Fig. 2. Left column of micrographs displays morphology of liver (a, b) and pancreatic cells (c, d) derived from non-addicted (a, c) and addicted $(\mathbf{b}, \mathbf{d})$ male rats. Tissues were stained with hematoxylin and eosin (HE). Non-addicted animals were exposed only to tobacco smoke $(\mathrm{T})$, and addicted males were exposed to tobacco smoke and were subsequently administered a single intragastric dose of ethanol (T \& E). Right column of micrographs depicts a variable PCNA protein expression within liver $(\mathbf{e}, \mathbf{f})$ and pancreatic $(\mathbf{g}, \mathbf{h})$ cells, which derived from the same rats - non-addicted $(\mathbf{e}, \mathbf{g})$ and addicted $(\mathbf{f}, \mathbf{h})$. Immunolabeling with PCNA antibody resulted in strong signal in nuclei of almost all cells derived from addicted animals $(\mathbf{f}, \mathbf{h})$. Nuclei of non-addicted rats showed relatively lower expression of PCNA $(\mathbf{a}, \mathbf{d})$. Cells with nucleocytoplasmic signal, indicating PCNA presence (arrows) must be noted especially in the pancreas (h) and liver (not shown) cells of addicted rats. The bars represent $50 \mu \mathrm{m}$

$2 \mathrm{~g}-\mathrm{h}$ ). It should be noted that the lack of PCNA stain in the nucleus suggests G0 phase of cell cycle. The 1+ suggest $\mathrm{G} 1$, while $2+/ 3+$ and simultaneous lack of cytoplasmic staining should be recognized as $\mathrm{S}$ phase. Moreover, cells with condensed nucleus and speckled cytoplasmic staining are in late $\mathrm{G} 2$ phase, just prior to going into mitosis [21]. In our experiment, to probe cellular proliferation, PCNA labeling index (PCNALI) were calculated by counting the number of immunohistochemically labeled nuclei in S-phase per total number of counted cells [21]. Obtained results are presented in Figure 2, Tables 2, 3 and 4 and are described below.
Tab. 2. PCNA-LI independent from harmful substances in liver and pancreas of non-addicted and addicted animals

\begin{tabular}{l|c|cc}
\hline \multirow{2}{*}{ Studied group } & Exposure & \multicolumn{2}{|c}{$\begin{array}{c}\text { Percentage of cells with PCNA } \\
\text { expression (\%) }\end{array}$} \\
\cline { 3 - 4 } & $\begin{array}{c}\text { Time } \\
(\mathrm{h})\end{array}$ & Liver & Pancreas \\
\hline 1- non-addicted & 5 & $12.89 \pm 2.83^{\star}$ & $16.37 \pm 4.49^{\star}$ \\
male (control) & 24 & $11.95 \pm 8.63$ & $7.57 \pm 4.62^{\star}$ \\
\hline $2-$ non-addicted & 5 & - & - \\
female (control) & 24 & - & - \\
\hline 3 - addicted male & 5 & $19.43 \pm 4.28^{\star}$ & $21.34 \pm 4.85^{\star \mathrm{a}}$ \\
& 24 & $15.70 \pm 2.90^{\mathrm{a}}$ & $17.60 \pm 4.80^{\star \mathrm{a}}$ \\
\hline 4 - addicted female & 5 & $15.07 \pm 6.55^{\mathrm{a}}$ & $12.51 \pm 5.15^{\mathrm{a}}$ \\
& 24 & $8.33 \pm 5.475^{\mathrm{a}}$ & $11.63 \pm 4.24^{\mathrm{a}}$ \\
\hline
\end{tabular}

* means significant differences $(p<0.05)$ in PCNA-LI of addicted males vs. control group. ${ }^{a}$ means significant differences $(p<0.05)$ in PCNA-LI of addicted males vs. addicted females

\section{PCNA labeling in the nucleus}

Significant similarities and differences in the intensity of PCNA protein synthesis regarding sex, ethanol addiction and type of administered harmful substance were observed in hepatic and pancreatic cells of rats (Fig. 2e-h; Tabs. 2 and 3).

Generally, while analyzing mean values of PCNALI (counted as a mean value of each subgroup belonging to addicted or non-addicted rats) we detected that addicted males (group 3) had the highest PCNA-LI vs. non-addicted animals (control group; Tab. 2). In addicted males, the percentage of cells with strongest expression of PCNA was approximately $21 \%$ for pancreatic cells and 19\% for liver rat cells (Tab. 2), whereas, for non-addicted males PCNA-LI was approximately $16 \%$ and $12 \%$, respectively (Tab. 2). There were statistically significant differences. Moreover, the comparison between addicted males and addicted females reveals that proliferation index in females is significantly $(\mathrm{p}<0.05)$ lower, both in hepatic and pancreatic tissues (Tab. 2).

Detailed results of PCNA-LI in respective subgroups of rats (after exposure to tobacco smoke or/and ethyl alcohol) are summarized in Table 3. The highest level of PCNA protein expression was observed in hepatic and pancreatic cells of addicted male rats, which were given only a single dose of ethanol and then, after $5 \mathrm{~h}$, sacrificed (group 3, sub- 
Tab. 3. PCNA-LI in hepatic and pancreatic cells of rats of both sexes, addicted and non-addicted to ethanol

\begin{tabular}{|c|c|c|c|c|c|c|c|}
\hline \multirow{3}{*}{ Studied group } & \multirow{3}{*}{$\begin{array}{l}\text { Exposure } \\
\text { Time } \\
\text { (h) }\end{array}$} & \multicolumn{6}{|c|}{ Subgroup } \\
\hline & & $\begin{array}{l}\text { A - tobacco } \\
\text { smoke }\end{array}$ & $\begin{array}{l}\text { B - ethyl } \\
\text { alcohol }\end{array}$ & $\begin{array}{c}\mathrm{C}-\text { tobacco } \\
\text { smoke and ethyl } \\
\text { alcohol }\end{array}$ & $\begin{array}{l}\text { A - tobacco } \\
\text { smoke }\end{array}$ & $\begin{array}{l}\text { B - ethyl } \\
\text { alcohol }\end{array}$ & $\begin{array}{c}\mathrm{C}-\text { tobacco } \\
\text { smoke and ethyl } \\
\text { alcohol }\end{array}$ \\
\hline & & \multicolumn{3}{|c|}{$\begin{array}{l}\text { Liver - percentage of cells with PCNA expression } \\
(\%)\end{array}$} & \multicolumn{3}{|c|}{\begin{tabular}{|c|} 
Pancreas - percentage of cells with PCNA expression \\
$(\%)$
\end{tabular}} \\
\hline \multirow{2}{*}{$\begin{array}{l}1 \text { - non-addicted male } \\
\text { (control) }\end{array}$} & 5 & $13.0 \pm 0.72$ & $11.4 \pm 4.56^{\star}$ & $14.2 \pm 2.21$ & $13.9 \pm 1.27$ & $17.3 \pm 7.19$ & $17.9 \pm 3.72$ \\
\hline & 24 & $12.3 \pm 3.47$ & $21.3 \pm 3.44^{\mathrm{a}}$ & $2.2 \pm 0.30 * a$ & $6.8 \pm 3.61$ & $10.3 \pm 6.13$ & $5.6 \pm 4.16$ \\
\hline \multirow{2}{*}{$\begin{array}{l}2 \text { - non-addicted female } \\
\text { (control) }\end{array}$} & 5 & - & - & - & - & - & - \\
\hline & 24 & - & - & - & - & - & - \\
\hline \multirow[t]{2}{*}{3 - addicted male } & 5 & $15.2 \pm 0.87$ & $24.3 \pm 2.74^{*}$ & $18.9 \pm 1.50$ & $17.8 \pm 1.82$ & $22.4 \pm 6.17$ & $23.8 \pm 4.79$ \\
\hline & 24 & $12.5 \pm 1.54$ & $17.3 \pm 1.95$ & $17.3 \pm 2.08^{*}$ & $19.6 \pm 2.75$ & $18.5 \pm 5.07$ & $14.8 \pm 6.33$ \\
\hline \multirow[t]{2}{*}{4 - addicted female } & 5 & $10.0 \pm 1.91^{\mathrm{a}}$ & $11.7 \pm 1.27$ & $23.4 \pm 2.54^{\mathrm{a}}$ & $10.2 \pm 2.58$ & $9.3 \pm 1.71$ & $18.0 \pm 5.28$ \\
\hline & 24 & $3.1 \pm 0.86^{\mathrm{a}}$ & $6.6 \pm 0.61^{\mathrm{a}}$ & $15.3 \pm 0.87^{\mathrm{a}}$ & $8.2 \pm 2.06$ & $11.8 \pm 5.24$ & $14.9 \pm 2.65$ \\
\hline
\end{tabular}

\pm SD (standard deviations); ${ }^{2}$ means significant differences $(p<0.05)$ in PCNA-LI in subgroups A or B vs. subgroup $C,{ }^{*}$ means significant differences $(p<0.05)$ in PCNA-LI in different variants of experiments vs. control group

group B; Tab. 3). The percentage of PCNA positive cells in this group amounted to $24.3 \pm 2.74 \%$ for liver and $22.4 \pm 6.17 \%$ for pancreas tissue, whereas for non-addicted males (control group) the percentage of these cells was lower and amounted to $11.4 \pm 4.56 \%$ and $17.3 \pm 7.19 \%$, respectively. However, statistically significant differences were noticed only for liver tissues (Tab. 3). It is worth noting that equally high proliferation index (but not statistically significant) was observed also in pancreatic cells derived from addicted males exposed to tobacco smoke plus alcohol, and it amounted to $23.8 \pm 4.79 \%$, while in the control it was $17.9 \pm 3.72 \%$ (Tab. 3 ).

Immunohistocheminal studies of the liver in addiction reflected a significant increase in PCNA-LI from $2.2 \pm 0.30 \%$ for control animals to $17.3 \pm 2.08 \%$ for addicted males exposed simultaneously to tobacco smoke and ethanol and then sacrificed after $24 \mathrm{~h}$ after administering harmful substances. Thus, the expression level of PCNA is almost 8 times higher compared to the control group (Tab. 3). Similar patterns of PCNA expression were revealed for pancreas tissue. PCNA-LI in addicted males exposed to tobacco smoke and ethyl alcohol was higher almost 3 times in relation to non-addicted males, but this difference was not statistically significant (Tab. 3).

Exposure of rats only to tobacco smoke does not have significant influence on PCNA-LI (Tab. 3). The results relating to this group suggest that in addicted rats the number of cells with PCNA at level 3 (Sphase) slightly increased in comparison to cells of control groups. PCNA-LI for liver cells increase from $13.0 \pm 0.72 \%$ (control) to $15.2 \pm 0.87 \%$ (addicted males exposed to tobacco) and for pancreatic cells it looked similar - $13.9 \pm 1.27 \%$ (control) vs. 17.8 $\pm 1.82 \%$ (addicted male exposed to tobacco).

The comparison between subgroups demonstrated another pattern of PCNA expression. PCNA-LI in each of the experimental groups (non-addicted male and addicted male and female) was low for hepatic and pancreatic tissues derived from rats exposed to tobacco, higher for animals exposed to ethanol and the highest for animals administered both tobacco smoke and ethanol. The fact that tobacco smoke plus alcohol treatment and alcohol alone induced more proliferation of nuclei in the liver than tobacco treatment alone is better illustrated in Figure $2(\mathrm{e}-\mathrm{h})$. These differences were statistically significant only for liver tissues derived from some subgroups of non-addicted males and addicted females (Tab. 3). For the remaining groups, even though the differences are not explicit, they present a particular trend, the same as described above, in cell reaction to a specific stimulus.

Furthermore, the number of cells with strong PCNA expression in nucleus decreased three times on average (in group 4, subgroup A - from $10.0 \%$ to 
Tab. 4. Percentage of cells with both nucleo-cytoplasmic PCNA protein expression in hepatic and pancreatic cells of rats of both sexes, addicted and non-addicted to ethanol

\begin{tabular}{|c|c|c|c|c|c|c|c|}
\hline \multirow{3}{*}{ Studied group } & \multirow{3}{*}{$\begin{array}{l}\text { Exposure } \\
\text { Time } \\
\text { (h) }\end{array}$} & \multicolumn{6}{|c|}{ Subgroup } \\
\hline & & $\begin{array}{l}\text { A - tobacco } \\
\text { smoke }\end{array}$ & $\begin{array}{l}\text { B - ethyl } \\
\text { alcohol }\end{array}$ & $\begin{array}{c}C-\text { tobacco } \\
\text { smoke and ethyl } \\
\text { alcohol }\end{array}$ & $\begin{array}{l}\text { A - tobacco } \\
\text { smoke }\end{array}$ & $\begin{array}{l}\text { B - ethyl } \\
\text { alcohol }\end{array}$ & $\begin{array}{c}\text { C - tobacco } \\
\text { smoke and ethyl } \\
\text { alcohol }\end{array}$ \\
\hline & & \multicolumn{3}{|c|}{$\begin{array}{l}\text { Liver - percentage of cells with PCNA expression } \\
(\%)\end{array}$} & \multicolumn{3}{|c|}{$\begin{array}{l}\text { Pancreas - percentage of cells with PCNA expression } \\
\qquad(\%)\end{array}$} \\
\hline \multirow{2}{*}{$\begin{array}{l}1 \text { - non-addicted } \\
\text { male (control) }\end{array}$} & 5 & $0.0^{\mathrm{a}}$ & $3.7 \pm 0.90 * a b$ & $0.0^{b}$ & $0.8 \pm 0.35^{\star a}$ & $5.6 \pm 0.91^{a b}$ & $0.7 \pm 0.32^{* b}$ \\
\hline & 24 & $0.0^{\mathrm{a}}$ & $6.8 \pm 0.71^{\star a b}$ & $0.0^{b}$ & $0.8 \pm 0.32^{*}$ & $1.7 \pm 0.46^{\star}$ & $0.5 \pm 0.21^{\star}$ \\
\hline \multirow{2}{*}{$\begin{array}{l}2 \text { - non-addicted } \\
\text { female (control) }\end{array}$} & 5 & - & - & - & - & - & - \\
\hline & 24 & - & - & - & - & - & - \\
\hline \multirow{2}{*}{3 - addicted male } & 5 & $0.2 \pm 0.06^{\mathrm{a}}$ & $5.8 \pm 0.96 * a b$ & $0.1 \pm 0.06^{b}$ & $1.7 \pm 0.25^{\star}$ & $2.8 \pm 0.56$ & $2.7 \pm 0.15^{\star}$ \\
\hline & 24 & $0.4 \pm 0.26^{a}$ & $10.6 \pm 1.22^{\star a b}$ & $0.2 \pm 0.06^{b}$ & $2.3 \pm 0.55^{\star}$ & $2.6 \pm 0.62^{\star}$ & $1.5 \pm 0.35^{\star}$ \\
\hline \multirow{2}{*}{4 - addicted female } & 5 & $0.4 \pm 0.15^{a}$ & $3.1 \pm 0.47^{a} b$ & $0.2 \pm 0.15^{b}$ & $2.9 \pm 0.32$ & $2.7 \pm 0.63$ & $3.8 \pm 1.10$ \\
\hline & 24 & $0.0^{\mathrm{a}}$ & $2.2 \pm 0.57^{\mathrm{a}}$ & $0.5 \pm 0.21$ & $1.6 \pm 0.25$ & $1.6 \pm 0.46$ & $0.8 \pm 0.35$ \\
\hline
\end{tabular}

\pm SD (standard deviations). ${ }^{a b}$ means significant differences $(p<0.05)$ in PCNA-LI between subgroups, ${ }^{*}$ means significant differences $(p<$ 0.05 ) in PCNA-LI in different variants of experiments vs. control group

3.1\%; Tab. 3) and in some cases even seven times (in group 1, subgroup $\mathrm{C}$ - from $14.2 \%$ to $2.2 \%$; Tab. 3 ) when the animal tissues were collected 24 instead of $5 \mathrm{~h}$ after toxic substance application. This tendency occurred repeatedly in all analyzed main study groups $-1,2,3$ and 4 . Inverse correlation was observed only in three situations: (1) in hepatic cells of non-addicted males which were given ethanol, (2) in pancreatic cells of addicted females which were given ethanol and (3) in pancreatic cells of addicted males which were exposed to tobacco smoke (Tab. 3).

\section{PCNA labeling in the cytoplasm}

It was demonstrated that cells with strong nucleocytoplasmic expression are most numerous in the liver of addicted animals which got a single dose of ethanol (group 3, subgroup B), and the percentage of cells in this group is 1.5 times higher in relation to control group (non-addicted males; Tab. 4). Similar results were observed for pancreatic cells of addicted males which were exposed only to tobacco smoke (group 3, subgroup A) and only to ethanol (group 3, subgroup B). The percentage of analyzed cells was approximately 3 times (for tobacco smoking) and 1.5 times (for ethanol) higher than in the control group (Tab. 4). These results are statistically significant. The most interesting in terms of pancreas tissue analysis is the subgroup $\mathrm{C}$ - animals which, at first, got a single dose of ethanol and then were exposed to tobacco smoke for 5 days (group 3, subgroup C; Tab. 4; Fig. $2 \mathrm{~g}-\mathrm{h}$ ). The percentage of pancreas cells with nucleocytoplasmic PCNA expression observed in this subgroup (C), increase 4 times in relation to pancreatic cells of non-addicted males (control) (Tab. 4).

\section{Discussion}

It was concluded from previous epidemiological studies that a majority of alcohol addicted people smoke tobacco [5]. Taking this fact into consideration, the researchers focused their attention on the analysis of the relationship between alcohol consumption and tobacco smoking because understanding and knowledge about interactions could become a breakthrough in addiction treatment.

In the current study, we have analyzed the effect of tobacco smoke, ethanol and both tobacco smoke and ethanol exposition on regeneration capacity of the liver and the pancreas derived from alcohol addicted and non-addicted male and female rats. Morphological studies revealed changes considered as adaptation 
to cell injury. Liver and pancreas of non-addicted males revealed a normal histoarchitecture, while liver of addicted animals (mainly those exposed to ethanol and simultaneously to tobacco smoke and ethanol) display significant damage, including fatty degradation, fibrosis and slight inflammatory infiltrate. However, pancreatic samples of addicted animals display only slightly derangements. Those differences between tissues probably were caused mainly by significantly less capacity for oxidative ethanol metabolism by the pancreas than that of the liver [24]. Other authors have demonstrated similar results that hepatic damage associated with chronic consumption of ethanol leads e.g., to an increase in the synthesis of fatty acids, triglycerides and biomarkers of oxidative stress, a decrease of fatty acids utilization and promotion of the infiltration of inflammatory leukocytes $[10,47]$.

Liver cells in normal conditions are characterized by very low replicative activity. Mitosis is observed only in approximately one out of 20,000 hepatocytes. The rest of parenchymal cells are in a G0 phase [48]. Similar situation could be observed in the pancreas. However, in response to specific environmental situations these organs have a remarkable ability to regenerate itself [14]. The image of low proliferation activity in the liver and the pancreas could be violated by e.g., partial hepatectomy, pancreatectomy or after toxical injury, virus infections, ischemia or hypoxia [10, 16, 29]. After that, hepatocytes and pancreatic cells and cooperating with them non-parenchymal cells take either proliferative efforts to organ regeneration or cancer development, necrosis or apoptosis [8].

In our studies, in order to examine the proliferation (regeneration) activity of hepatic and pancreatic cells, immunohistochemical analysis for PCNA was performed. This method is commonly used as a measure of hepatocyte regeneration in liver injury models [2, $3,14,21]$. PCNA is a $36-\mathrm{kDa}$ molecular weight auxiliary protein of DNA polymerase $\delta$ and is involved in a wide range of functions in the nucleus such as control of DNA replication, cell-cycle progression, transcription as well as DNA damage repair [28, 32]. The concentration of the PCNA protein in the nucleus increases in the final stage of G1 phase of the cell cycle and reaches maximum value in $S$ phase. Total absence of this protein could be observed in G0 phase [43, 44]. It is worth to note that a substantial amount of PCNA is also present in the cytoplasm, although their func- tion in this compartment is still not well elucidated. Speckled staining of PCNA in the cytoplasm and dense in the nucleus usually depicting cells just prior to going into mitosis, during late G2 phase [21]. In our studies, PCNA is present mainly in cellular nuclei of liver and pancreas cells. Only sparse cells of both organs had PCNA protein in cytoplasm. However, it is worth noticing that a considerably higher number of cells with nucleocytoplasmic location of PCNA antigen was found in the liver of addicted males exposed only to ethyl alcohol, in comparison to other studied subgroups and in comparison to non-addicted males and addicted females. An equally high level of PCNA protein synthesis in the cytoplasm was also observed in pancreatic cells of addicted male rats which were exposed to tobacco smoke and subsequently to ethanol. These data are statistically significant. We suggest that PCNA in cytoplasm is associated with glycolytic enzyme ( $\alpha$-enolase) and it could be involved in the regulation of last part of glycolysis pathway [36]. It is known that concentration of glycolytic enzymes increases in the cancer cells compared to normal cells [34]. Therefore, we hypothesize that liver cells derived from addicted males which were administrated a single intragastric dose of ethanol, and pancreas cells derived from addicted males exposed both to tobacco smoke and ethanol were in the most vulnerable to these harmful substances damage. It is worth remembering that almost $90 \%$ of ethanol is metabolized in the liver, and the pancreas is one of the organs where metabolic processes of tobacco smoke constituents take place. These facts may explain the highest number of cells with nucleocytoplasmic location of PCNA in the liver and the pancreas derived from ethanol addicted animals exposed to ethanol and ethanol plus tobacco smoke, respectively.

In the assessment of the influence of ethyl alcohol and tobacco smoke toxic compounds on cell proliferation of rat liver and pancreas, a diversified value of PCNA-labeling index, defined as the percentage of nuclei with positive PCNA staining in the total number of cells counted, was demonstrated.

Outcomes of numerous studies proved that the main ethanol metabolite - acetaldehyde - is a reactive compound, responsible for the majority of tissue and organ damages. Mainly the liver but also the pancreas is a targets of the toxic effects of acetaldehyde, because of their ability to metabolize alcohol $[25,52]$. Previous studies showed that ethanol feeding can induce a proliferative state in the liver of rats after 
a relative short-term of treatment (1-2 months) [2, 4, 11]. This notion was supported by our observations that in hepatic and pancreatic cells of ethanol addicted males (after 9 weeks feeding of alcohol) statistically significant higher values of PCNA-LI were found, in comparison with non-addicted rats. Furthermore, our data demonstrated that the strongest expression of proliferation antigen was observed in cells of ethanol dependent animals which were administered a single dose of ethanol and then, after $5 \mathrm{~h}$, sacrificed. The percentage of cells with the strongest expression in this group was approximately $24 \%$ for the liver and $22 \%$ for the pancreas. For the control group (nonaddicted males), the percentage of these cells was lower (statistically significant difference for liver and not significant for pancreas tissue). Our results proved that alcohol addiction promotes both liver and pancreas proliferation.

In contrast to the results described above, longterm ethanol rats' feeding (2, 6 and 10 months) inhibits both liver and pancreas proliferation and regeneration, assessed by Ki-67 and PCNA immunohistochemistry decreases $[9,37]$. This could be due to increased DNA repair, as it is important to mention that PCNA expression may occur just due to proliferation and due to DNA repair [28]. A decrease of proliferation by ethanol intake has been well documented in liver regeneration after partial hepatectomy [29]. However, in some studies, ethanol exposure can induce proliferative state in the livers of rats $[4,11]$. It is worth noticing that cessation of the ethanol treatment resulted in the recovery of the liver and the pancreas. Moreover, morphological regeneration was less pronounced and animals exposed to ethanol develop chronic calcifying pancreatitis [37]. Chronic ethanol intake additionally suppresses cell growth factors and cell cycle proteins, such as hepatocyte growth factor (HGF) and cyclin D1 [27, 29].

Another important and interesting finding of this study is that the comparison between addicted males and addicted females reveals that PCNA-LI in females is significantly lower, both in hepatic and pancreatic tissues. These results are surprising for us, because it is generally known that women appear to be at higher risk of alcoholic disease. Men metabolize alcohol more efficiently than women due to higher activity of gastric alcohol dehydrogenase, higher body size, lower body fat, and higher liver mass per kilogram of body weight. There are several studies demonstrating that women develop liver disease after ex- posure to lower quantities of alcohol and over shorter time periods $[6,23]$. Probably there was no gender difference when alcohol to be fed to animals was measured per kilogram of the liver. In our experiment females are characterized by lower percentage of PCNA positive cells. We can wonder why. One can assume that females are more sensitive to alcohol addiction and relatively large dose of ethanol used to female addiction caused a decrease in potential to regeneration of liver and pancreas.

However, it is not surprising for us that there was a high percentage of PCNA-positive hepatocytes and pancreatic cells in rats enrolled in subgroup C. These animals were exposed to tobacco smoke for 5 days and afterwards they were given a single intragastric dose of ethanol. A simultaneous effect of the two harmful factors should damage the organs to a greater extent. The obtained outcomes support this theory. Our data from immunohistochemical reactions are in agreement with some previous observations which suggest that alcohol and smoking have greater relative effect together than alone [40]. Additionally, moderate alcohol intake smokers produce markedly higher concentration of carcinogenic acetaldehyde in the oral cavity than non-smokers [26]. These results imply that chronic ethanol consumption with simultaneous cigarette smoking increases the rate of damages in cells, and thus increase regeneration potential of both the liver and the pancreas.

It is important to emphasize that hepatic and pancreatic cells of animals which were ethanol non-addicted and exposed only to tobacco smoke (subgroup A) are characterized by lower value of PCNA-LI, in comparison to other subgroups. So, exposure of rats only to tobacco smoke does not have significant influence on an increase of the regeneration potential. Additionally, it is worth to notice that in our experiments, tobacco smoke does not have influence on ethanol concentration in blood of non-addicted (male, female) and addicted (male, female) animals. We also proved, that chronic administration of alcohol did not influence on nicotine metabolism in all animals exposed to tobacco smoke.

Another pattern was usually observed in cells of organs collected $24 \mathrm{~h}$ after toxic substance administration, which had lower PCNA expression in comparison to cells obtained $5 \mathrm{~h}$ after exposure to studied xenobiotics. A three-fold (e.g., from 10.0 to 3.1\%) and in some cases nearly seven-fold decrease of PCNA expression (e.g., from 14.2 to $2.2 \%$ ) were observed. It can be assumed that these differences are associated 
with an increase in the activity of cells' regeneration mechanism within the first hours after exposure to toxic substances.

From the preliminary study one can conclude that ethanol alone and simultaneous influence of ethanol and tobacco smoke impair liver and pancreatic functions to a greater degree than tobacco abuse. In order to confirm this observation it is necessary to (1) extend the experimental groups, (2) apply additional cell proliferation markers and (3) confirm the presence and level of expression of other proteins related to tobacco smoke and ethanol metabolism. These are the conditions required for full understanding of the processes occurring in the liver and the pancreas under influence of tobacco smoke or/and ethanol.

\section{Acknowledgments:}

The studies were partially supported by project from the Polish Ministry of Science and Higher Education (no. N N401 153538 and N N401 082 136) and from Nicolaus Copernicus University (no. 05/2010). Authors thank Ms. Anna Michalska-Orlik for professional linguistic correction of the manuscript.

\section{References:}

1. Albano E: Alcohol, oxidative stress and free radical damage. Proc Nutr Soc, 2006, 65, 278-290.

2. Apte UM, McRee R, Ramaiah SK: Hepatocyte proliferation is the possible mechanism for the transient decrease in liver injury during steatosis stage of alcoholic liver disease. Toxicol Pathol, 2004, 32, 567-576.

3. Assy N, Gong Y, Zhang M, Pettigrew NM, Pashniak D, Minuk GY: Use of proliferating cell nuclear antigen as a marker of liver regeneration after partial hepatectomy in rats. J Lab Clin Med, 1998, 131, 251-256.

4. Baroni GS,Marucci L, Benedetti A, Mancini R, Jezequel AM, Orlandi F: Chronic ethanol feeding increases apoptosis and cell proliferation in rat liver. J Hepatol, 1994, 20, 508-513.

5. Batel P, Pessione F, Maitre C, Rueff B: Relationship between alcohol and tobacco dependencies among alcoholics who smoke. Addiction, 1995, 90, 977-980.

6. Becker U, Deis A, Sørensen TI, Grønbaek M, BorchJohnsen K, Müller CF, Schnohor P, Jensen G: Prediction of risk of liver disease by alcohol intake, sex, and age: a prospective population study. Hepatology, 1996, 23, 1025-1029.

7. Buchholz M, Kestler HA, Holzmann K, Ellenrieder V, Schneiderhan W, Siech M, Adler G et al.: Transcriptome analysis of human hepatic and pancreatic stellate cells: organ-specific variations of a common transcriptional phenotype. J Mol Med, 2005, 83, 795-805.
8. Cavalla R, Liang BG: Mutagenesis, tumorigenicity and apoptosis: are the mitochondria involved? Mut Res, 1998, 398, 19-26.

9. Chavez PR, Lian F, Chung J, Liu C, Paiva SA, Seitz HK, Wang XD: Long-term ethanol consumption promotes hepatic tumorigenesis but impairs normal hepatocyte proliferation in rats. J Nutr, 2011, 141, 1049-1055.

10. Chmielewski M, Kaczmarek E, Roszyk E, Piertas S, Linke K: Hepatocyte regeneration in alcoholic liver injury. Gastroenterol Pol, 2009, 16, 429-435.

11. Colantoni A, Idilman R, De Maria N, La Paglia N, Belmonte J, Wezeman F, Emanuele N et al.: Hepatic apoptosis and proliferation in male and female rats fed alcohol: role of cytokines. Alcohol Clin Exp Res, 2003, 27, 1184-1189.

12. Chowdhury P, Rayford PL: Smoking and pancreatic disorders. Eur J Gastroenterol Hepatol, 2000, 12, 869-877.

13. Corrigall WA, Coen KM, Adamson KL: Selfadministered nicotine activates the mesolimbic dopamine system through the ventral tegmental area. Brain Res, 1994, 653, 278-284.

14. Elsässer HP, Adler G, Kern HF: Replication and regeneration of the pancreas. In: Pancreas: Biology, Pathology, and Disease, Ed. Go VLW, Raven Press Ltd., New York, 1993, chapter 5, 75-86.

15. Epstein M: Alcohol's impact on kidney function. Alcohol Health Res World, 1997 21, 1, 84-92.

16. Fausto N: Liver regeneration. J Hepathol, 2000, Suppl 1, 1, 19-31.

17. Florek E, Ignatowicz E, Piekoszewski W: Effect of pregnancy and tobacco smoke on antioxidant activity of rutin in animal model. Pharmacol Rep, 2009, 61, 935-940.

18. Florek E, Marszałek A: An experimental study of the influences of tobacco smoke on fertility and reproduction. Hum Exp Toxicol, 1999, 18, 272-278.

19. Florek E, Piekoszewski W, Kluza M, Szindżikaszwili T, Gomółka E, Chuchracki M, Sędziak A: Interaction between tobacco smoke and alcohol in animal models. Pharmacol Rep, 2008, 60, 985-990.

20. Florek E, Piekoszewski W, Rybakowski L, Moczko J: Using the questionnaire and cotinine concentration in urine for study smoking habit and exposure to ETS of pregnant women (Polish). Przegl Lek, 2004, 61, 993-996.

21. Foley JF, Dietrich DR, Swenberg JA, Maronpot RR: Detection and evaluation of proliferating cell nuclear antigen (PCNA) in rat tissue by improved immunohistochemical procedure. J Histotech, 1991, 4, 237-241.

22. Frazier TH, Stocker AM, Kershner NA, Marsano LS, McClain CJ: Treatment of alcoholic liver disease. Therap Adv Gastroenterol, 2011, 4, 63-81.

23. Fuchs CS, Stampfer MJ, Colditz GA, Giovannucci EL, Manson JE, Kawachi I, Hunter DJ et al.: Alcohol consumption and mortality among women. N Engl J Med, 1995, 332, 1245-1250.

24. Haber PS, Apte MV, Applegate TL, Norton ID, Korsten MA, Pirola RC, Wilson JS: Metabolism of ethanol by rat pancreatic acinar cells. J Lab Clin Med, 1998, 132, 294-302.

25. Hammamoto T, Yamada S, Hirayama C: Nonoxidative metabolism of ethanol in the pancreas; implication in al- 
coholic pancreatic damage. Biochem Pharmacol, 1990, 39, 241-245.

26. Homann N, Tillonen J, Meurman J, Rintamäki H, Lindqvist C, Rautio M, Jousimies-Somer H, Salaspuro M: Increased salivary acetaldehyde levels in heavy drinkers and smokers: a microbiological approach to oral cavity cancer. Carcinogenesis, 2000, 22, 663-668.

27. Hsu MK, Qiao L, Ho V, Zhang BH, Zhang H, Teoh N, Dent P, Farrell GC: Ethanol reduces p38 kinase activation and cyclin D1 protein expression after partial hepatectomy in rats. J Hepatol, 2006, 44, 375-382.

28. Kelman Z: PCNA: structure, functions and interactions. Oncogene, 1997, 14, 629-640.

29. Koteish A, Yang S, Lin H, Huang J, Diehl AM: Ethanol induces redox-sensitive cell-cycle inhibitors and inhibits liver regeneration after partial hepatectomy. Alcohol Clin Exp Res, 2002, 26, 1710-1718.

30. Kumar V, Cotran R: Robbins S: Robbins' Pathology (Polish). Elsevier Urban \& Partner, Wrocław, 2008.

31. Larsson A, Engel JA: Neurochemical and behavioral studies on ethanol and nicotine interactions. Neurosci Biobehav Rev, 2004, 27, 713-720.

32. Lee MY, Zhang S, Lin SH, Chea J, Wang X, Leroy C, Wong A: Regulation of human DNA polymerase delta in the cellular responses to DNA damage. Environ Mol Mutagen, 2012, 53, 683-698.

33. Lieber CS: Microsomal ethanol-oxidizing system (MEOS): The first 30 years (1968-1998) - a review. Alcohol Clin Exp Res, 1999, 23, 991-1007.

34. Macheda ML, Rogers S, Best JD: Molecular and cellular regulation of glucose transporter (GLUT) proteins in cancer. J Cell Physiol, 2005, 202, 654-662.

35. Marrero, JA, Fontana RJ, Fu S, Conjeevaram HS, Su GL, Lok AS: Alcohol, tobacco and obesity are synergistic risk factors for hepatocellular carcinoma. J Hepatol, 2005, 42, 218-224.

36. Naryzhny SN, Lee H: Proliferating cell nuclear antigen in the cytoplasm interacts with components of glycolysis and cancer. FEBS Lett, 2010, 584, 4292-4298.

37. Pap A, Boros L: Alcohol-induced chronic pancreatitis in rats after temporary occlusion of biliopancreatic ducts with Ethibloc. Pancreas, 1989, 4, 249-255.

38. Pelucchi C, Gallus S, Garavello W, Bosetti C, La Vecchia C: Alcohol and tobacco use, and cancer risk for upper aerodigestive tract and liver. Eur J Cancer Prev, 2008, 17, 340-344.

39. Rose JE, Brauer LH, Behm FM, Cramblett M, Calkins K, Lawhon D: Psychopharmacological interactions between nicotine and ethanol. Nicotine Tob Res, 2004, 6, 133-144.
40. Salaspuro MP: Alcohol consumption and cancer of the gastrointestinal tract. Best Pract Res Clin Gastroenterol, 2003, 17, 679-694.

41. Sata N, Koizumi M, Nagai H: Alcoholic pancreatopathy: a proposed new diagnostic category representing the preclinical stage of alcoholic pancreatic injury. J Gastroenterol, 2007, 42, Suppl 17, 131-134.

42. Schoedel KA, Tyndale RF: Induction of nicotinemetabolizing CYP2B1 by ethanol and ethanol-metabolizing CYP2E1 by nicotine: summary and implications. Biochim Biophys Acta, 2003, 1619, 283-290.

43. Selzner M, Clavien PA: Failure of regeneration of the steatotic rat liver: disruption at two different levels in the regeneration pathway. Hepatology, 2000, 31, 35-42.

44. Selzner N, Selzner M, Tian Y, Kadry Z, Clavien PA: Cold ischemia decreases liver regeneration after partial liver transplantation in the rat: a TNF- $\alpha$ /IL-6-dependent mechanism. Hepatology, 2002, 36, 812-818.

45. Slack JM: Developmental biology of the pancreas. Development, 1995, 121, 1569-1580.

46. Śliwińska-Mosson M, Milnerowicz H: Tobacco smoking and the diseases of pancreas (Polish). Przegl Lek, 2005, $62,1163-1166$.

47. Sommerfeld K, Zielińska-Psuja B, Przystanowicz J, Kowalówka-Zawieja J, Orłowski J: Effect of 4-methylpyrazole on antioxidant enzyme status and lipid peroxidation in the liver of rats after exposure to ethylene glycol and ethyl alcohol. Pharmacol Rep, 2012, 64, 1547-1553.

48. Söderpalm B, Ericson M, Olausson P, Blomqvist O, Engel JA: Nicotinic mechanisms involved in the dopamine activating and reinforcing properties of ethanol. Behav Brain Res, 2000, 113, 85-96.

49. Söderpalm B, Löf E, Ericson M: Mechanistic studies of ethanol's interaction with the mesolimbic dopamine reward system. Pharmacopsychiatry, 2009, 42, Suppl 1, S87-94.

50. Steer CJ: Liver regeneration. FASEB J, 1995, 9, 1396-1400.

51. Werner J, Laposata M, Fernandez-del Castillo C, Saghir M, Iozzo RV, Lewandrowski KB, Warshaw AL: Pancreatic injury in rat induced by fatty acid ethyl ester, a nonoxidative metabolite of alcohol. Gastroenterology, 1997, 113, 286-294.

52. Werner J, Saghir M, Fernandez-del Castillo C, Warshaw AL, Laposata M: Linkage of oxidative and nonoxidative ethanol metabolism in the pancreas and toxicity of nonoxidative ethanol metabolites for pancreatic acinar cells. Surgery, 2001, 129, 736-744.

Received: January 29, 2012; in the revised form: February 4, 2013; accepted: February 16, 2013. 